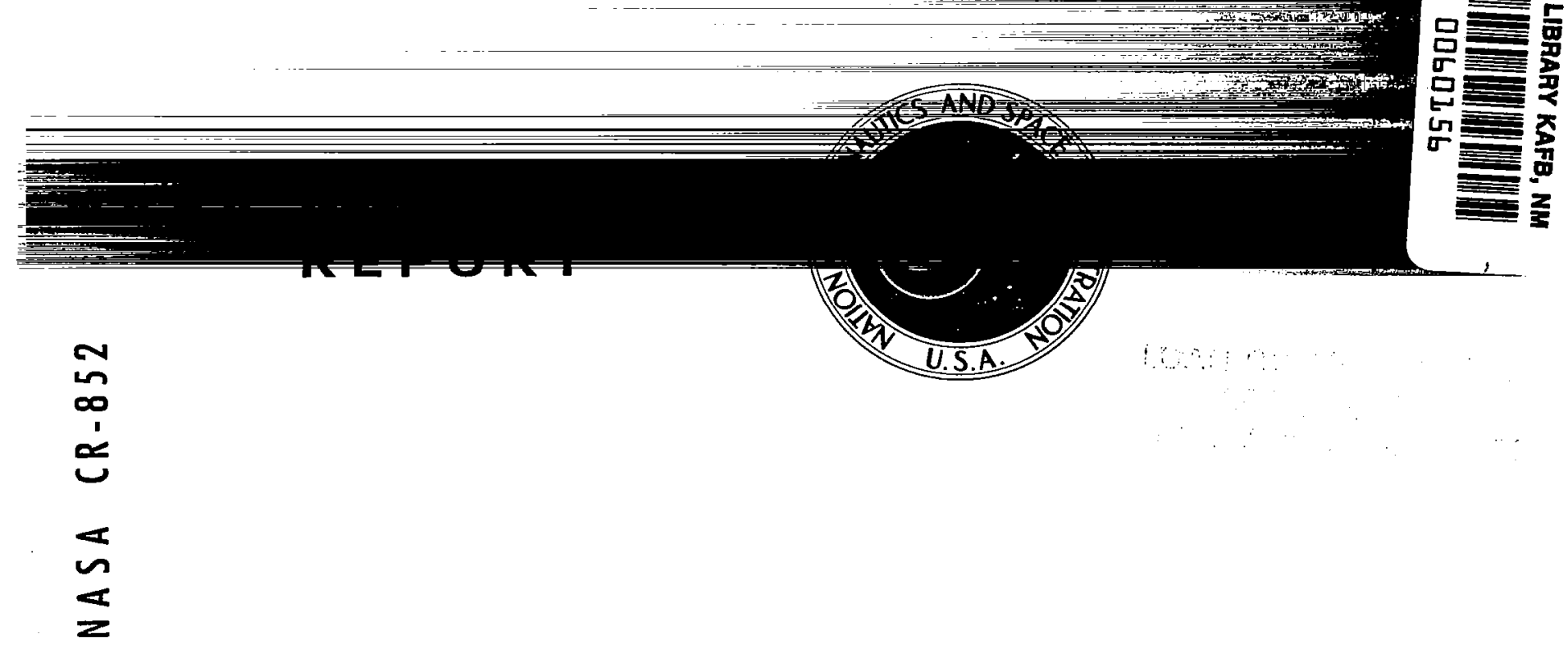

\title{
INJECTION OF A DRAG-REDUCING FLUID INTO TURBULENT PIPE FLOW OF A NEWTONIAN FLUID
}

by C. Sinclair Wells, Jr., and Jack G. Spangler

Prepared by

LTV RESEARCH CENTER

Dallas, Texas

for

NATIONAL AERONAUTICS AND SPACE ADMINISTRATION - WASHINGTON, D. C. - JULY 1967 


\section{INJECTION OF A DRAG-REDUCING FLUID INTO}

TURBULENT PIPE FLOW OF A NEWTONIAN FLUID

By C. Sinclair Wells, Jr., and Jack G. Spangler

Distribution of this report is provided in the interest of information exchange. Responsibility for the contents resides in the author or organization that prepared it.

Issued by Originator as Report No. 0-71000/7R-4

Prepared under Contract No. NASw-729 by

LTV RESEARCH CENTER

Dallas, Texas

for

NATIONAL AERONAUTICS AND SPACE ADMINISTRATION

For sale by the Clearinghouse for Federal Scientific and Technical Information Springfield, Virginia 22151 - CFSTI price $\$ 3.00$ 


\author{
Injection of a Drag-Reducing Fluid into \\ Turbulent P1pe Flow of a Newtonian Fluld \\ by \\ C. Sinclair Wells, Jr., and Jack G. Spangler \\ LIV Research Center \\ Dallas, Texas
}

\begin{abstract}
Recent experiments with adiftives which reduce turbulent skin friction in turbulent shear flow of liquids have suggested that the slgniflcant changes in the shear flow occur in the flow very near the wall, in the region of the viscous sublayer. i series of experiments, in whtch dilute solutions of drag-reducing flufds were injected into turbulent pipe flow of a Newtonian fluid, were performed in order to determine whether the presence of the additive only in the wall region could produce signiflcant local shear stress reduction. It was found that the local pressure gradient could be reduced by an amount comparable to the flow of a unfform concentration when the fluid was injected in the wall region. Conversely,
\end{abstract}


when the fluid was injected into the turbulent core no reduction in local pressure gradient occurred until the fluid diffused into the wall region. The effects of the injection flow process and the injection apparatus were evaluated and found to be small compared to the results of injection of the drag-reducing flutd.

\section{INIRODUCTION}

This paper describes an experiment to determine whether local injection of very dilute solutions of drag-reducing additives (Toms effect ${ }^{1,2}$ ) into a turbulent shear flow causes significant viscous drag reduction. In particular, the physical reasoning that the significant changes in the turbulent shear layer occur in the viscous sublayer region, as shown by recent studies $3-7$, was to be tested by injecuion both at the wall and in the turbulent core. The effects of the injection process itself were known to cause some drag reduction $^{8}$, and they were taken into account through additional experiments.

Although recent advances have been made in the explanation of the drag reduction mechanism of dilute polymer solutions ${ }^{9-i l}$ a complete theory which would predict the effect based on molecular characteristics has not been achieved. An empirical correlation whlch satisfactorily predicts the reduction in wall friction has been accomplished, based on observations of a thickened viscous sublayer and no change in the mixing length distribution tor very dilute solutions ${ }^{5}$. In order to obtain a theoretical description of the process, the energy budget through the shear layer must be determined, as was done by Laufer ${ }^{12}$ for Newtonian flutds. Since the viscous sublayer plays what seems to be a controlling role in the energy budget of drag-reducing fluids, it is important to determine the effects of the additive in the suid- 
layer, while it is absent from the turbulent core, and vice versa. That was the primary purpose of these experiments; although, the practical benefits of demonstrating significant drag reduction by putting additive in only a small portion of the total shear flow were not to be 1gnored.

\section{EXPERIMENTAL PROCEDURES}

A plexiglas tube test section was added downstream of an intermittent run pipe flow facility test section (see Ref. 6 for a description of tine facility and instrumentation) with provisions for injecting various fluids either through a clrcumferential, ten-degree angle, 1/8-1nch slot in the tube wall or through a 5/16-inch diameter tube on the pipe centerline. The test section for injection is shown in Fig. 1. Both test-sections were 1.50-inches in diameter, and water flowing at a pipe Reynolds number of $.85 \times 10^{5}$ was the turbulent shear flow into which the other fluids were injected. The following fluids were used in the injection apparatus: (1) water, (2) a 0.1 percent by weight solution of a guar gum ( $J-2 P$, a product of the Western Company, Dallas, Texas) in water, (3) a 0.01 percent by weight solution of a copolymex of polyacrylamide and polyacrylic acid ( $P-295$, a product of the Stein-Hall Company, New York) in water, and (4) a solution of corn syrup and water having a viscosity about 5 times that of water. Injection rates at both locations were varied from about 1 percent to 5 percent of the total mass flow through the pipe $\left(1 \%<\mathbb{n}_{\text {inj }} / \mathbb{H}_{\text {total }}<5 \%\right)$. This can be compared with the mass flow in the viscous sublayer of about 3 percent of the total mass flow. The local pressure gradients at several stations up to 40 pipe radil downstream from the point of injection were measured. Flow visualization with dye injection showed that the injected fluld remained near the wall for 
several pipe radil when injected through the wall, and remained near the centerline for several pipe radil, when injected at the centerline. A reasonably uniform concentration of the injected dye was observed at about 20 radii from the point of injection for wall injection and at about 12 radif for centerline injection. There was no observed difference in the aye pattern between injection of water and the drag-reducing fluids.

RESULTS AND DISCUSSION

Both drag-reducing fluids were tested to determine their arag-reducing properties in ordinary pipe flow. The data were applied to the correlation ${ }^{5}$

$$
\begin{aligned}
& \frac{1}{f^{\frac{1}{2}}}=\left[4+\frac{\alpha}{(2)^{\frac{1}{2}}}\left(\frac{n}{2-n}\right)\right] \log _{10} R_{e_{w}} f^{\frac{1}{2}}-.394+\frac{\alpha}{(2)^{\frac{2}{2}}} \log _{10} \\
& {\left[\frac{u_{* c r} D^{\frac{n}{2-n}}(2)^{\frac{n}{2(2-n)}}}{(a / \rho)^{\frac{1}{2-n}}}\right]}
\end{aligned}
$$

where: $f=\frac{\tau_{w}}{\frac{z}{2} \rho \bar{u}^{2}}$, friction factor; $\tau_{\mathrm{w}}=\frac{R}{2} \frac{\Delta p}{\Delta \mathrm{x}}$, wall shear stress; $R$ is pipe radius, $D / 2 ; R_{e_{w}}=\frac{\bar{u} D}{v_{v}} ; \bar{u}$ is bulk velority; $v_{w}$ is kinematic viscosity evaluated at the wall; $\alpha$ is the drag-reduction parameter; $u_{* C r}=\left(\tau_{N} / \rho\right)^{\frac{1}{2}}$ the critical shear stress, above which drag-reduction occurs; and $\rho$ j.s fluid density which is unchanged by the additive.

$v_{w}$ was determined to be $2.65 \times 10^{-5} \mathrm{ft}^{2} / \mathrm{sec}$ for the 0.1 percent $J-P \mathrm{P}$ solution and $1.06 \times 10^{-5} \mathrm{ft}^{2} / \mathrm{sec}$ for the 0.01 percent $\mathrm{P}-295$ solution st the flow rate of the injection experiment. This is compared vith $v_{w}=1.02 \times 10^{-5}$ $\mathrm{ft}^{2} / \mathrm{sec}$ for water at the test conditions. For the J-2P solution, $\alpha=34.4$ 
and $u_{* c r}=0.21 \mathrm{ft} / \mathrm{sec}$; and for the $\mathrm{P}-295$ solution, $\alpha=21.3$ and $u_{* c r}=0.15$ $\mathrm{ft} / \mathrm{sec}$. The J-2P solution data used to determine the correlation parameters are shown in Fig. 2, together with the correlation line. The same type of data for the P- 295 solution are not shown since the data taken in one of the pipes apparently was degraded. Degradation was not a problem with the injected solutlons, however.

The results of injection of water at the wall and on the centerline are shown in Figs. 3 and 4, respectively. Data for several injection rates are shown, as well as for the case of no injection which indicates the local disturbances only due to Irregularity in geometry. The ordinate vartable displayed is the difference between the measured friction factor for injection of water, $f_{\mathrm{N}_{i n j}}$, and the friction factor for a smooth surface (which is given by Eq. (1) for $\alpha=0$ ), $f_{N}$, divided by $f_{N} \cdot \bar{x}$ is distance from the point of injection to the midpoint between the corresponding two static pressure taps. The data indicate a reduction in friction factor just downstream from the point of injection for both wall and centerline injection. Downstream from about $\overline{\mathrm{X}}=12 \mathrm{R}$ there is a slight increase in local friction factor, but the change is less than 8 percent everywhere downstream from $\vec{x}=6 R$, except one station for centerline injection shown In Fig.4. In the data reduction for injection of arag-reducing fluids the effects of injection of water and of the injection geometry were taken into account by subtracting the friction factors for the injection of water from the measured friction factors.

The effects of injecting the high viscosity corn syrup solution is shown in Fig. 5 for both wall and centerline injection. The measured friction ractor for water injection, $\mathrm{F}_{\mathrm{N}_{\text {inj }}}$, is subtracted from the measured firiction factor for 
the corn syrup solution, $\mathrm{f}_{\mathrm{NNN}_{\text {inj }}}$, and the difference is divided by $f_{\mathrm{N}^{*}}$ Centerline injection gives a deviation in $f$ of less than 4 percent downstream from $\bar{x}=6 R$, with a slight increase in $f$ far from the point of injection. Wall Injection gives a reduction in $f$ near the point of injection with an increase up to 8 percent appearing at about $\bar{X}=8 \mathrm{R}$. This increase diminishes downstream to about a 2 percent increase far from the slot. This jndicates that the local friction factor for wall injection is increased for an increase in viscosity of a Newtonian injectant fluid. The increase appears only after the reduction due to the injection itself, and before the viscosity at the wall is decreased by diffusion. This is a significant result since the 0.1 percent $\mathrm{J}-2 \mathrm{P}$ solution has a kinematic viscosity about 2.5 times that of watcr; and if the local friction factor is to be decreased by the additive the effect must overcome the effect of the increased viscosity.

Figure 6 shows the effect of injecting the 0.1 percent solution of $J-2 P$ at the wall. Here the $f$ for injection of water was subtracted from the $f$ for injection of $\mathrm{J}-2 \mathrm{P}$ and the result was divided by the smooth-wall Newtonian friction factor. It should be noted that the ordinate scale has been conpressed by a factor of 10, compred to the previous data plots. The data show $f$ to be reduced for all injection rates, with the reduction becoming less for downstream stations, as the concentration near the wall decreases due to diffusion. The small drag-reduction shown near the slot is probably an effect of the injection geometry and because of large changes in pressure gradient over short distances in that region the data cannot be considered to have good accuracy. Note that for the lowest injection rate, and presumably the smallest local effect of injection itself, this minimum does 
not appear in the data.

Predictions of the friction factor reduction were made from the correlation expression for the cases of unfform concentrations of 0.1 percent and 0.005 percent $J-2 P$, which should correspond to the concentrations near the wall at the injection point and far downstream, respectively (for the case of the maximum injection mass ratio). The prediction was made for a 0.005 percent solution assuming a linear variation of $\alpha$ with concentration and no variation of $u_{* e r}$ with concentration. The predicted difference in friction factors at the Reynolds number based on the viscosity of the $Q I$ percent J-2P solution is 37 percent, which is less than the maximum reduction observed. If the v1scosity of water is used to determine the Reynolds number, the predicted reduction is 70 percent, which is greater than observed. Because of diffusion, the reduction should be between the two predicted values. Also, the data indicate a process which more than compensates for the increase in viscosity of the drag-reducing solution. By assumption of a linear variation of $\alpha$ with concentration, the reduction in $f$ predicted for a 0.005 percent concentration is about 4 percent for the maximum injection rate shown. This is less than the asymptote of about 10 percent which the data seem to approach downstream, which suggests that the solution very near the wall is diffused more slowly than the dye pattern indicates. It is possible that the linear interpolation is not correct at that low concentration, but those data are not available at this time. This suggested effect would, of course, work in favor of drag reduction by injection of small amounts of polymer solution at the wall.

Data for injection of the $\mathrm{J}-2 \mathrm{P}$ solution at the centerline are shown in 
Fig. 7. The data show the local friction factor to be increased or unchanged upstream, of the region where the injected dye was observed to reach the wall at an $\overline{\mathrm{X}}$ of about 12 radif, and to be decreased downstream of that region. This further confirms the idea of the effectiveness of the drag-reducing fluid in the wall region. The reductions in $f$ are smaller than for wall injection, of course, since the concentration is reduced by diffusion before the additive reaches the wall. The predicted reduction in friction factor for a 0.005 percent solution of J-2P (which is a uniform solution far downstream from the injection point for the maximum injection rate) is about 4 percent. This prediction agrees fairly well with the measured values, once the flutd reaches the wall region.

The data for injection of P-295 at the wall is shown in Fig. 8. For this much more effective additive there is also a significant reduction in $f$, with a maximum reduction of about 55 percent. This compares with a maximum reduction of about 35 percent predicted from the correlation for a uniform concentration. (There is no question about the Reynolds number here, since the P-295 solution has almost the same viscosity as water). The friction factor far downstream is also reduced more than would be predicted by assuming complete diffusion. The predicted reduction in $f$ far downstream is about one percent for the maximum injection rate. Therefore, the rall effect of the drag-reducing fluid is also shown for this very effective fluid.

\section{CONCLUSIONS}

The following conclusions can be stated, based on the experimental observations:

1. The effects of the injection apparatus on the local pressure gradient 
are small compared to the drag-reduction effects.

2. Dilute solutions of drag-reducing fluids in turbulent shear flow cause appreciable reduction of local pressure gradient when the drag-reducing additives are only in the region of flow near the wall.

3. Conversely, dilute solutions of drag-reducing f'luids do not reduce the local pressure gradient unless they are present in the region of flow near the wall.

4. The magnitude of observed pressure gradient reduction is greater than that predicted if the viscosity of the drag-reducing fluid is assumed for the case of wall injection, for fluids where the viscosity is greater than that for water, but the observed magnitude is close to the predicted value if the viscosity of water is assumed. That is, it is suggested that the local drag-reduction effect is not diminished due to the increased viscosity of the injected fluid.

5. The local pressure gradient far downstream of wall injection is reduced more than predicted for a fully diffused injectant, whereas the reduction is about as predicted far downstream of centerline injection. This Indicates that the diffusion from the wall flow region is relatively slow and maintains the concentration of the additive at a significantly high level; although, these calculations are not sufficiently accurate to prove this point due to a lack of detailed information about the drag-reduction properties of very dilute (trace) solutions.

6. Further experiments are needed to better define the diffusion of drag-reducing fluids in turbulent shear flow. 


\section{ACKNOWLEDGEMENTS}

This work is part of a project supported jointly by independent research and development funds of Ling-Temco-Vought, Inc., and the National Aeronautics and Space Administration under Contract No. NASw-729 (Fluid Physics Branch of the Research Division, OART). 


\section{REFERENCES}

1. B. A. Toms, Proc. Intem. Congr. Rheol., Holland, 1948, North-Holland Publ., Amsterdam, 1949), p. II-135.

2. J. G. Savins, J. Inst. Petrol. 47, 329 (1961).

3. C. S. Wells, A. I. A. A. J. 3, 1800 (1965).

4. W. D. Ernst, A. I. Ch. F. J. 12, 581 (1966).

5. W. A. Meyer, A. I. Ch. E. J. 12, 522 (1966).

6. W. D. Ernst, A. I. A. A. J. (to be published) (1967).

7. C. S. Wells, Jr., J. Harkness, and W. A. Meyer, ITV Research Center Report No. 0-71000/6R-22 (1966) (submitted for publication).

8. J. G. Spangler, NASA CR-634 (1966).

9. J. L. Lumley, Phys. Fluids, I, 190 (1964).

10. A. G. Fabula, J. L. Lumley and W. D. Taylor, Modern Developments in the Mechanics of Continua (Academic Press, New York, 1966), p. 145.

11. H. Tennekes, Phys. Fluids, 9, 872 (1966).

12. J. Laufer, NACA Report 1174 (1954). 


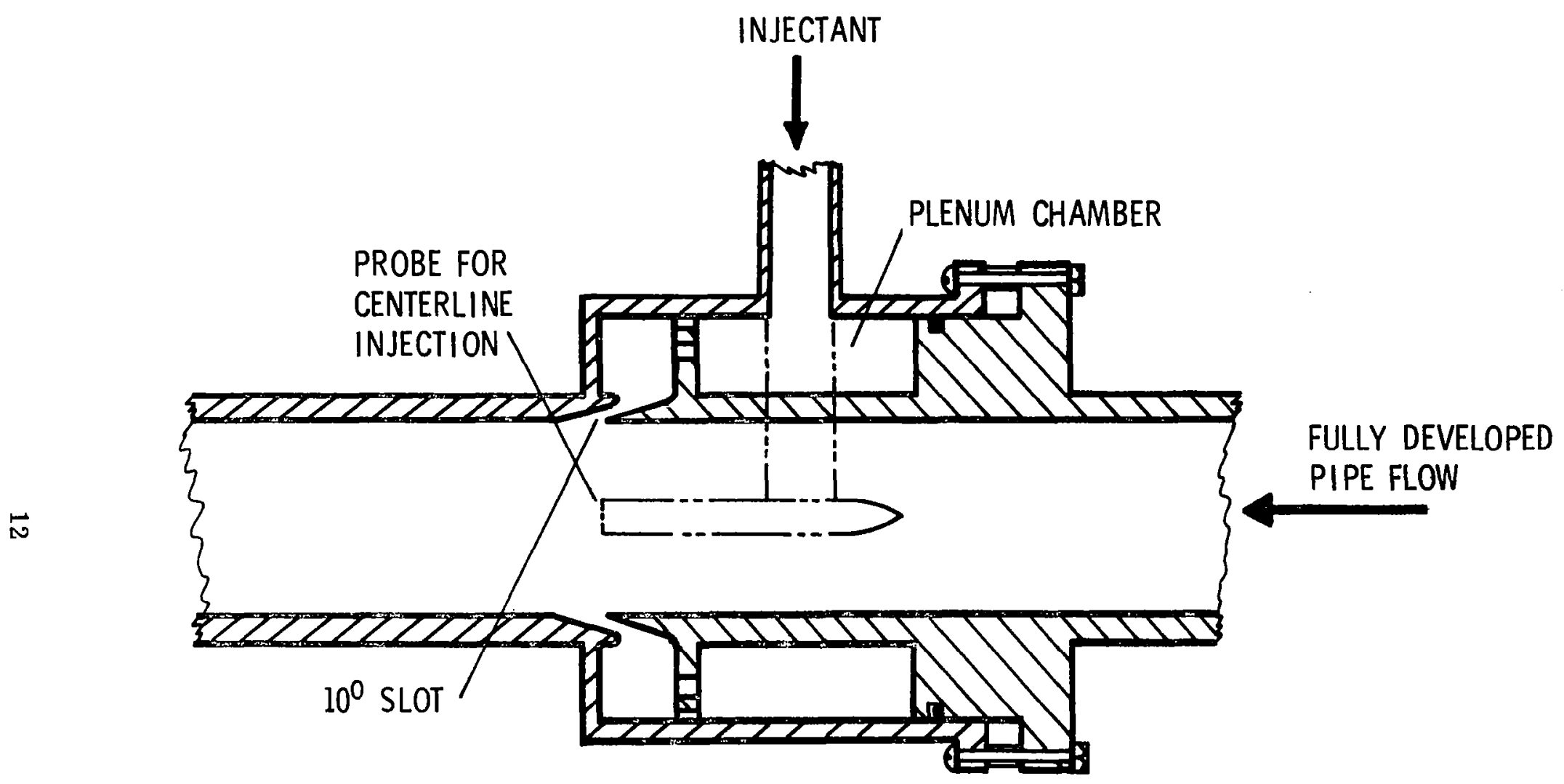

Figure 1 Sketch of test section for fluid injection. 


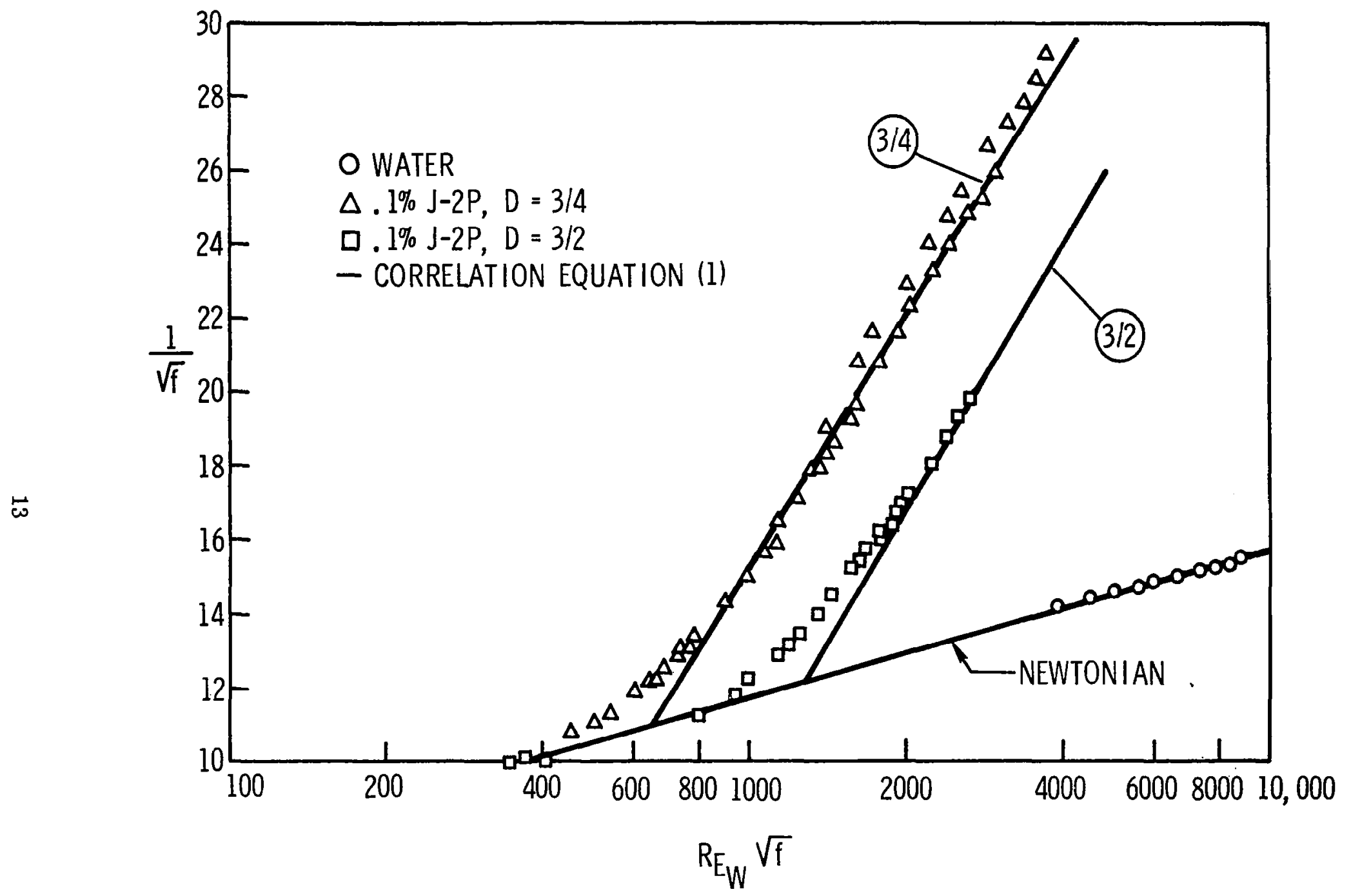

Figure 2 Correlation of data for a uniform solution of 0.1 percent $J-2 P$ in turbulent pipe flow. 


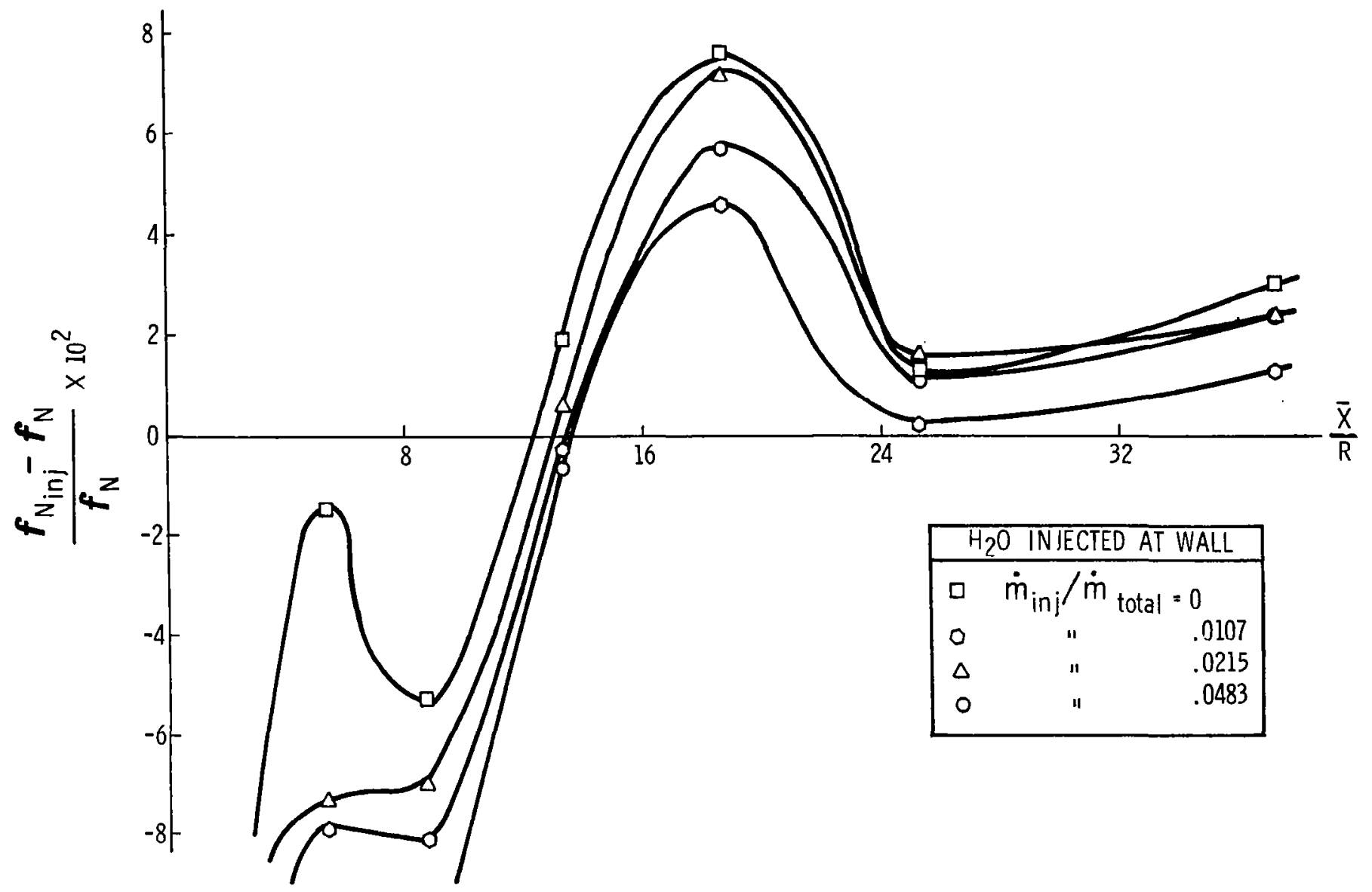

Figure 3 Local reduced friction factors for injection of water at the pipe wall. 


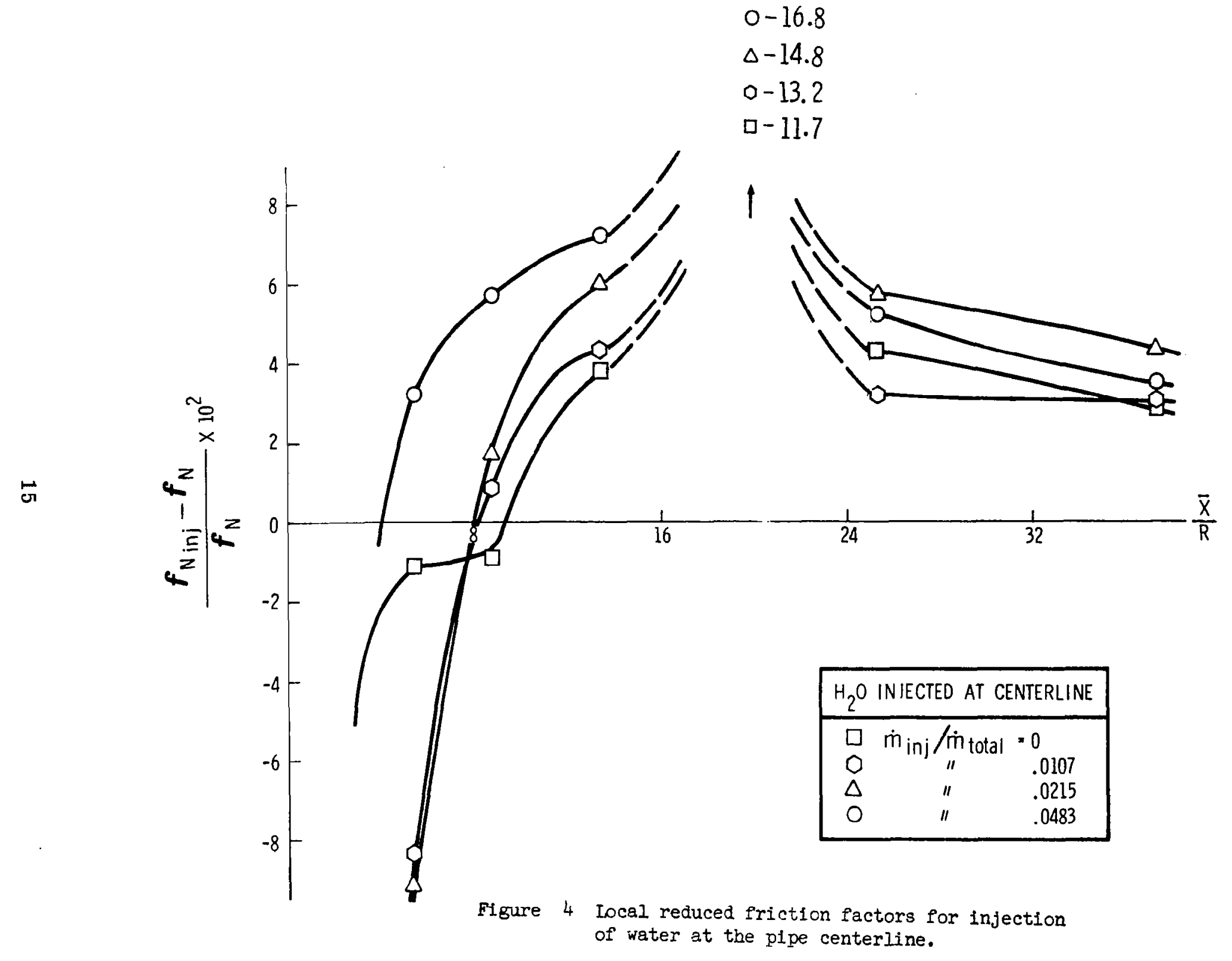




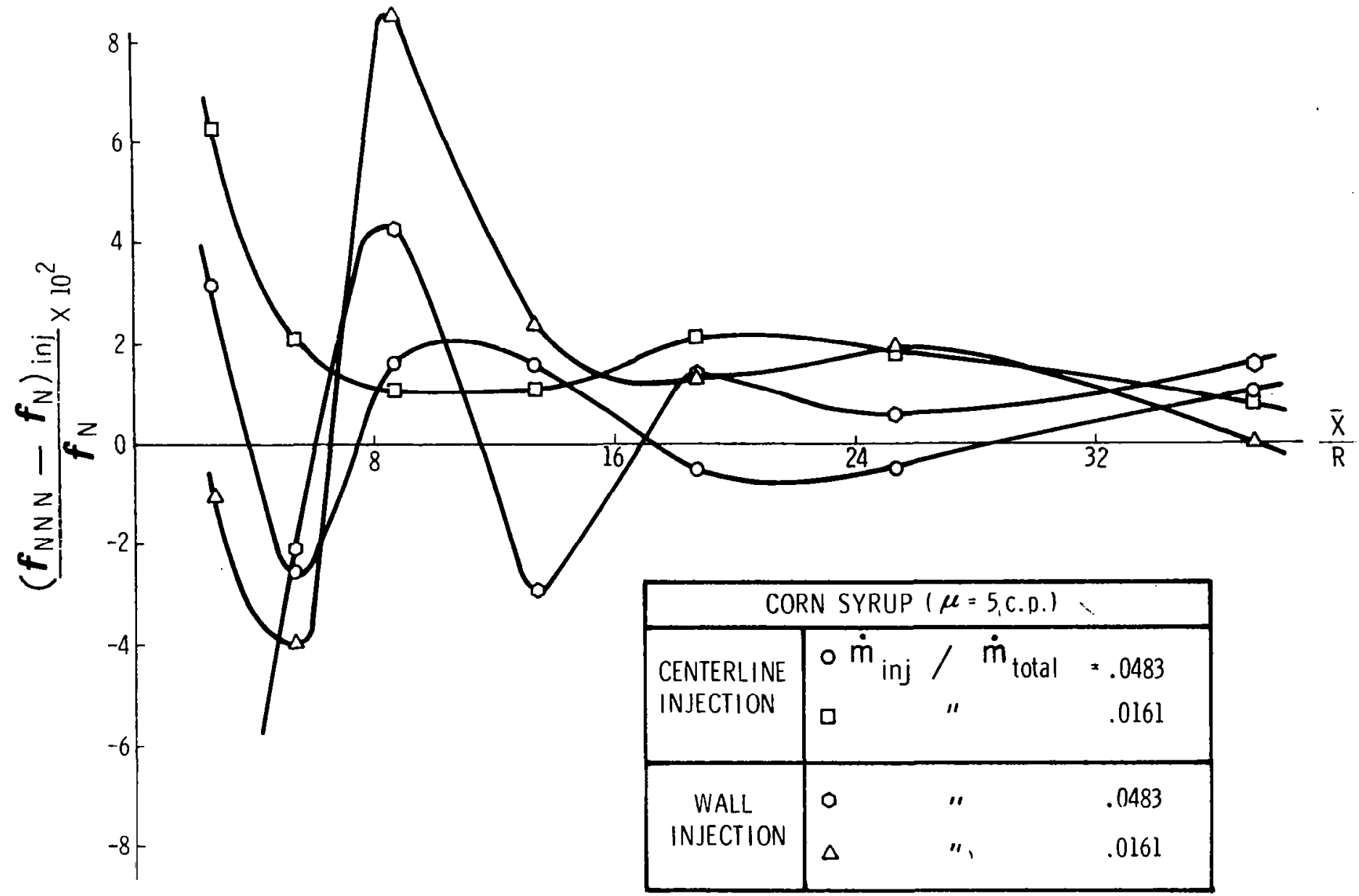

Figure 5 Local reduced friction factors for injection of the corn syrup solution at the pipe wall and at the centerline. 


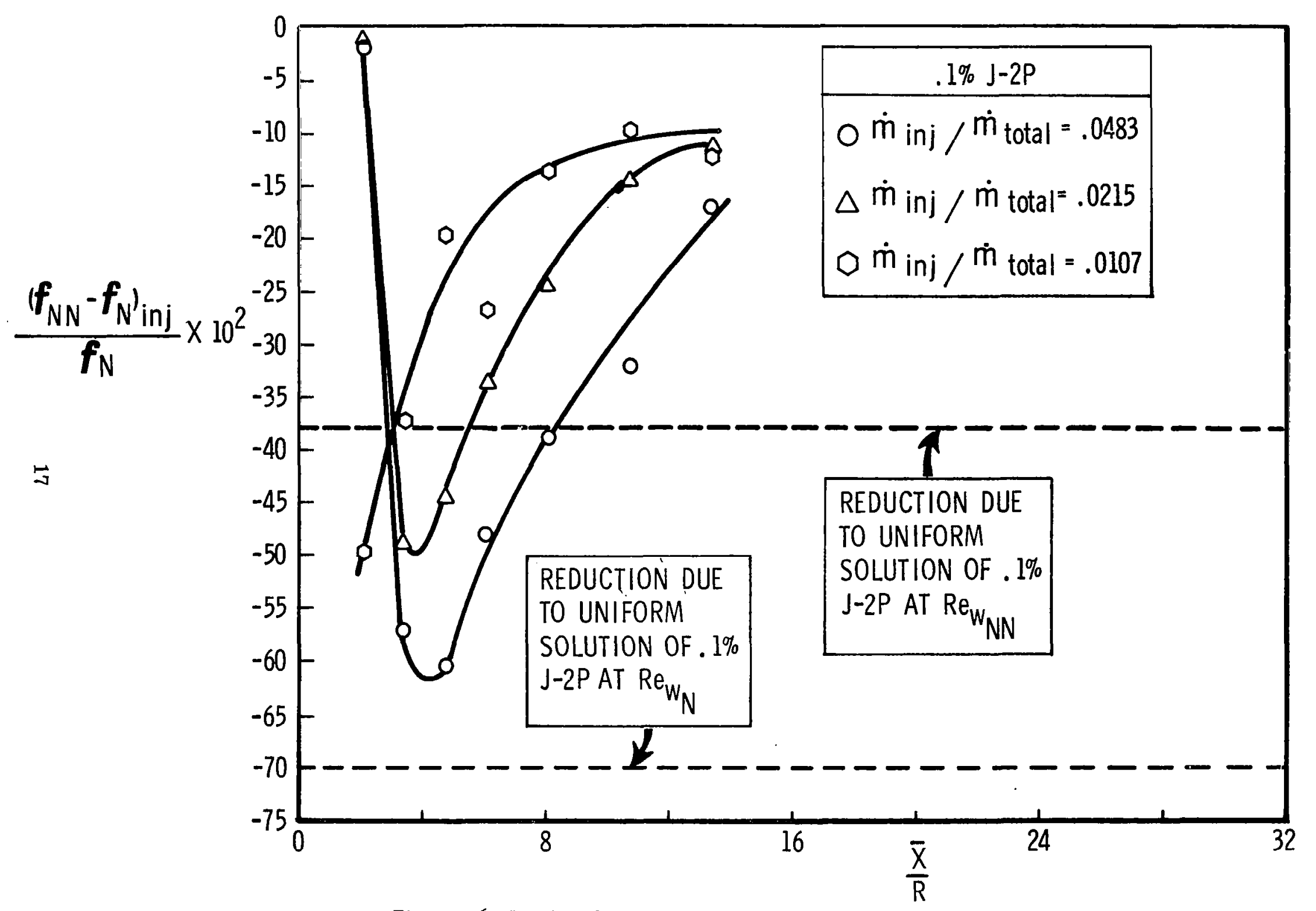

Figure 6 Local reduced friction factors for injection of 0.1 percent $I-2 P$ at the pipe wall. 


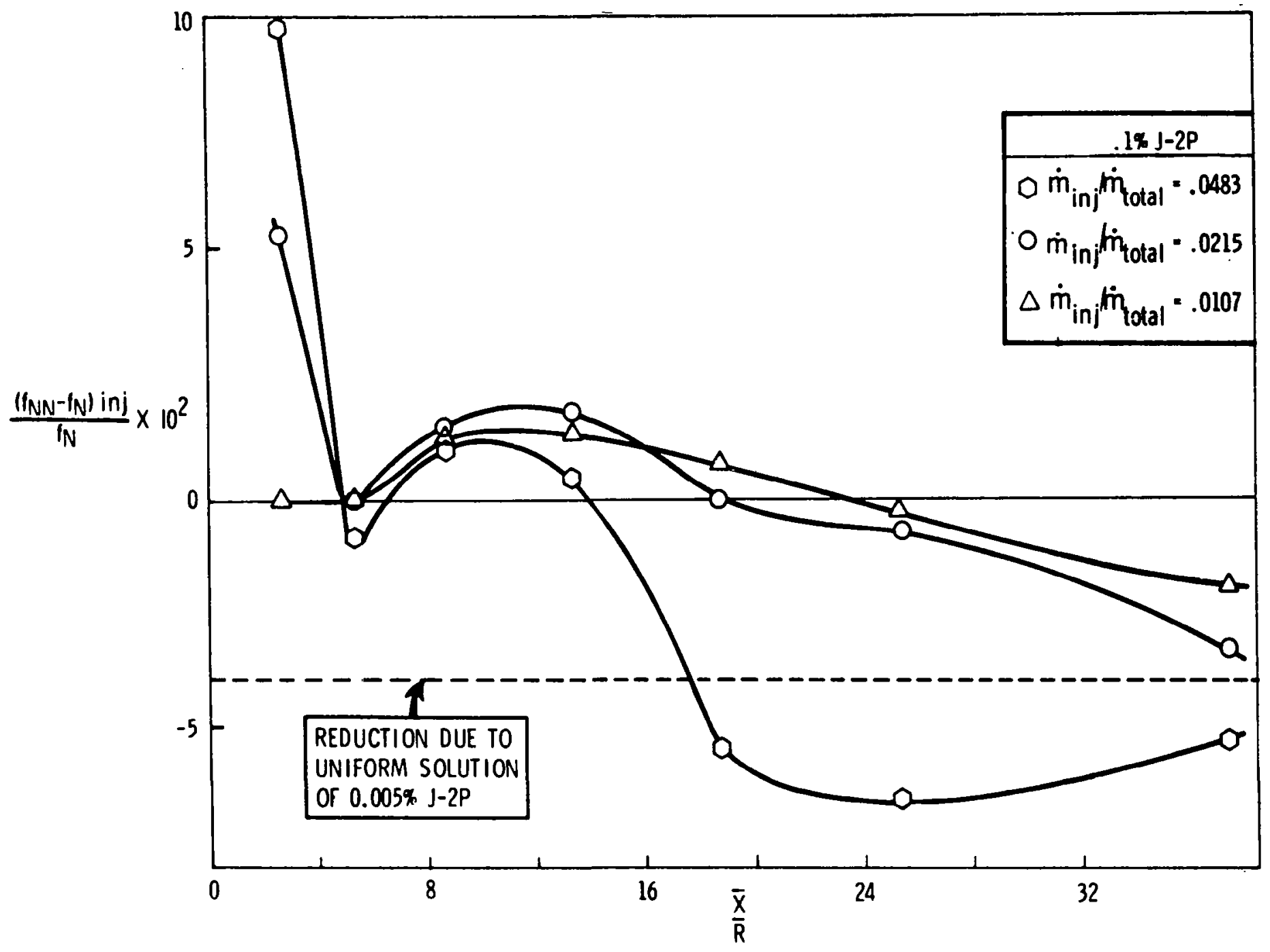

F4gure 7 Local reduced friction factors for injection of 0.1 percent $J-2 P$ at the pipe centerline. 


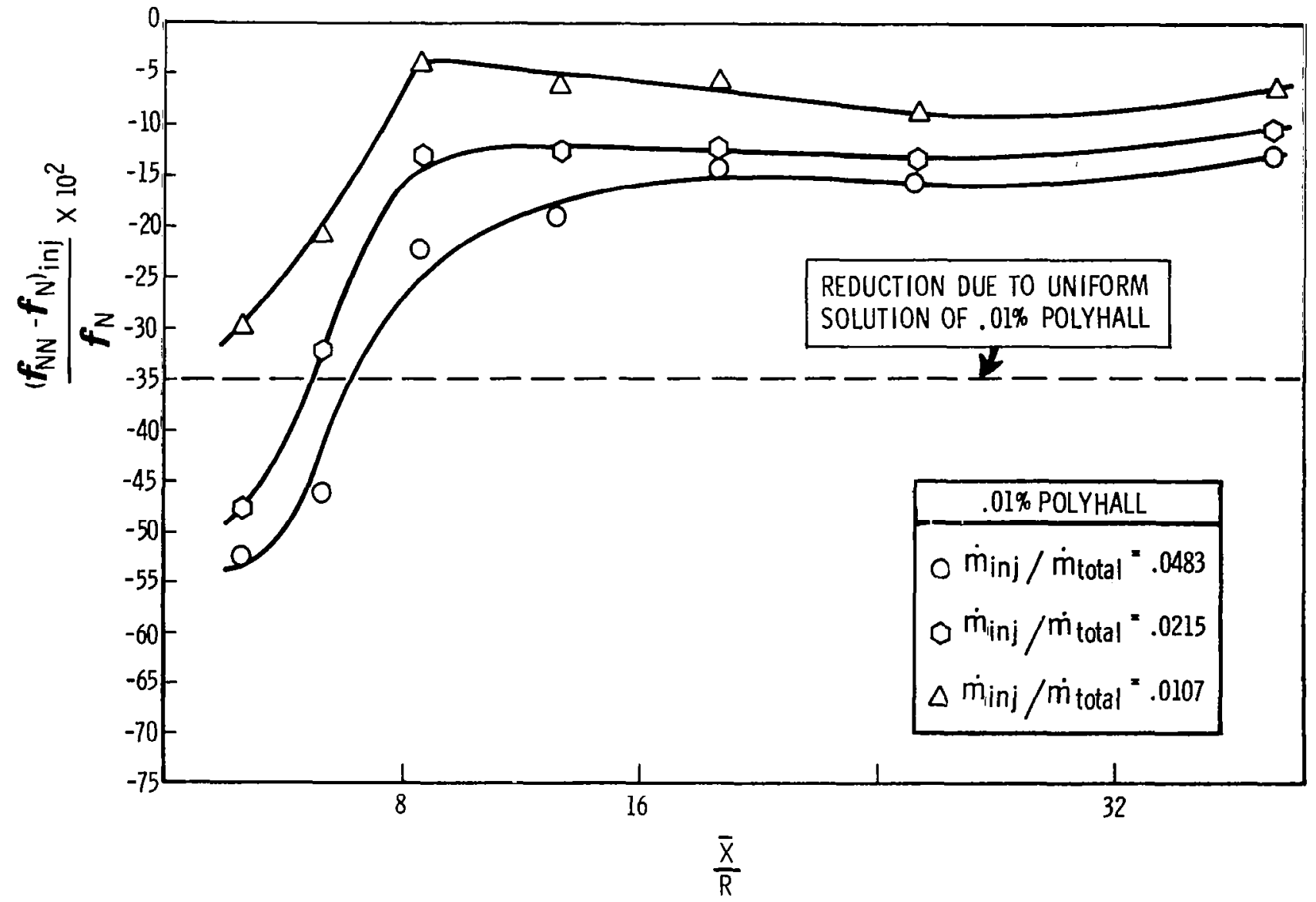

F1gure 8 Iocal reduced friction factors for injection of 0.01 percent $P-295$ at the pipe wall. 
"The aeronantical and space activities of the United States shall be conducted so as to contribute . . . to the expansion of buman knowledge of phenomena in the atmosphere and space. The Administration shall provide for the widest practicable and appropriate dissemination of information concerning its activities and the results thereof."

-National Aeronautics and Space Act of 1958

\section{NASA SCIENTIFIC AND TECHNICAL PUBLICATIONS}

TECHNICAL REPORTS: Scientific and technical information considered important, complete, and a lasting contribution to existing knowledge.

TECHNICAL NOTES: Information less broad in scope but nevertheless of importance as a contribution to existing knowledge.

TECHNICAL MEMORANDUMS: "Information receiving limited distribution because of preliminary data, security classification, or other reasons.

CONTRACTOR REPORTS: Scientific and technical information generated under a NASA contract or grant and considered an important contribution to existing knowledge.

TECHNICAL TRANSLATIONS: Information published in a foreign language considered to merit NASA distribution in English.

SPECIAL PUBLICATIONS: Information derived from or of value to NASA activities. Publications include conference proceedings, monographs, data compilations, handbooks, sourcebooks, and special bibliographies.

TECHNOLOGY UTILIZATION PUBLICATIONS: Information on technology used by NASA that may be of particular interest in commercial and other non-aerospace applications. Publications include Tech Briefs, Technology Utilization Reports and Notes, and Technology Surveys.

Details on the availability of these publications may be obtained from:

SCIENTIFIC AND TECHNICAL INFORMATION DIVISION

NATIONAL AERONAUTICS AND SPACE ADMINISTRATION

Washington, D.C. 20546 